\title{
Hypocholesterolaemic effects of milk-kefir and soyamilk-kefir in cholesterol-fed hamsters
}

\author{
Je-Ruei Liu ${ }^{1 *}$, Sheng-Yao Wang ${ }^{2}$, Ming-Ju Chen ${ }^{2}$, Hsiao-Ling Chen ${ }^{3}$, Pei-Ying Yueh ${ }^{4}$ and Chin-Wen Lin ${ }^{2}$ \\ ${ }^{1}$ Department of Biotechnology, National Formosa University, Yunlin, Taiwan \\ ${ }^{2}$ Department of Animal Science, National Taiwan University, Taipei, Taiwan \\ ${ }^{3}$ Department of Molecular Biotechnology, Da-Yeh University, Changhua, Taiwan \\ ${ }^{4}$ Council of Agriculture, Executive Yuan, Taipei, Taiwan
}

(Received 19 September 2005 - Revised 12 January 2006 - Accepted 20 January 2006)

\begin{abstract}
This study aimed to evaluate the hypocholesterolaemic property of milk-kefir and soyamilk-kefir. Male hamsters were fed on a cholesterol-free or cholesterol-enriched diet containing $10 \%$ skimmed milk, milk-kefir, soyamilk or soyamilk-kefir for a period of 8 weeks. The soyamilk, milk-kefir and soyamilk-kefir diets all tended towards a lowering of serum triacylglycerol and total cholesterol concentrations, and a reduction of cholesterol accumulation in the liver, the decrease in serum cholesterol concentration being mainly in the non-HDL fraction. The soyamilk-kefir diet led to a significant increase in the faecal excretion of neutral sterols and bile acids compared with the other two diets. The soyamilk-kefir diet also elicited a significant decrease in the serum ratio of non-HDL-cholesterol to HDL-cholesterol, compared with the control, than was the case for the other diets. These findings demonstrate that soyamilk-kefir may be considered to be among the more promising food components in terms of preventing CVD through its hypocholesterolaemic action.
\end{abstract}

Kefir: Soyamilk: Plasma lipid: Cholesterol: Hamster

CVD, defined as a range of diseases of the heart and circulatory system, is the most important cause of death in Westernized countries. A high level of serum total cholesterol is generally considered to be a risk factor for CVD. It would therefore appear to be very important to decrease elevated serum cholesterol levels in particular in order to prevent CVD (Hasler, 2002). Much attention has thus been drawn to elucidating different dietary means of reducing an individual's serum cholesterol level. Many nutritional and medical investigations have revealed the great potential of soya protein for lowering serum cholesterol level and the incidence of CVD, particularly for hypercholesterolaemic subjects (Carroll \& Kurowska, 1995; Demonty et al. 2003; Ascencio et al. 2004). A number of different mechanisms of action may be applied to explain the beneficial effects of soya protein as regards cholesterolaemia. A decrease in the intestinal absorption of cholesterol and/or bile acids, an increase in plasma cholesterol clearance through enhancing hepatic LDL-receptor activity and changes in the hepatic biotransformation of cholesterol can all be implicated in the range of possible mechanisms (Potter, 1995).

Since the early studies of Mann \& Spoerry (1974), there appears to have been an increasing interest in the hypocholesterolaemic activity of fermented dairy products. A number of studies have been performed with experimental animals, and also human subjects, in order to elucidate the effect of fermented dairy products on serum cholesterol (Anderson \& Gilliland, 1999; St-Onge et al. 2000; Xiao et al. 2003). Although some contradictory results have been obtained (Nakajima et al. 1992; de Roos et al. 1998), the majority of results from these reports indicate that fermented dairy products, possibly including kefir, possess hypocholesterolaemic properties.

Kefir is an acidic and mildly alcoholic fermented dairy product that is believed to contain many functional substances, and it has been postulated that the longevity of Bulgarian peasants is partially due to their frequent consumption of this fermented milk (Gilliland, 1990). In Soviet countries, kefir has, anecdotally, been recommended for consumption by healthy people in order to lower the risk of chronic diseases, and has also been provided to certain patients for the clinical treatment of a number of gastrointestinal and metabolic diseases, hypertension, IHD and allergy (St-Onge et al. 2002; Farnworth \& Mainville, 2003). Kefir differs from other fermented dairy products in that it is the product of fermentation of milk in the presence of a mixed group of microflora confined to a matrix of discrete 'kefir grains', which are recovered subsequent to fermentation (Marshall \& Cole, 1985). Various lactic acid bacteria and yeasts have been identified as being present in kefir grains, including Lactobacillus breris, L. helveticus, L. kefir, Leuconostoc mesenteroides, Kluyveromyces lactis, 
K. marxianus and Pichia fermentans (Angulo et al. 1993; Lin et al. 1999). The micro-organisms contained within the kefir grains typically produce lactic acid, antibiotics and several kinds of bactericide, such products inhibiting the proliferation of both degrading and pathogenic microorganisms in kefir milk (Angulo et al. 1993). Furthermore, kefir cultures are reported to possess the ability to assimilate cholesterol in milk (Vujicic et al. 1992).

In as much as kefir and soyabean are beneficial to health, we attempted in previous studies to produce soyamilk-kefir and were able to demonstrate that it possessed significant antimutagenic and antioxidant activity in vitro (Liu et al. 2002a, 2005). We also demonstrated that orally administered soyamilk-kefir not only inhibited tumour growth but also increased the total IgA level within the small intestine of mice (Liu et al. 2002b). To the best of our knowledge, however, it is not yet known whether the consumption of soyamilk-kefir will produce a hypocholesterolaemic effect in soyamilk-kefir consumers.

The aim of the present study was to investigate the effect of soyamilk-kefir on plasma and liver lipids. The levels of cholesterol and triacylglycerol in the plasma and liver, and of faecal bile acids and neutral sterols, in hamsters fed on a cholesterol-free or cholesterol-enriched diet with soyamilkkefir were analysed in order to evaluate the cholesterol-lowering property of soyamilk-kefir.

\section{Material and methods}

\section{Preparation of soyamilk}

Dry, mature, whole soyabeans $(1 \mathrm{~kg})$ were soaked in 3 litres distilled water at $25^{\circ} \mathrm{C}$ for $24 \mathrm{~h}$. The soak water was then decanted, and the beans were washed and then ground in 6 litres boiling distilled water in a blender (Waring Division, Dynamics Corporation, New Hartford, CT, USA). The resulting suspension was filtered through three layers of cheesecloth, autoclaved for $15 \mathrm{~min}$ at $121^{\circ} \mathrm{C}$, and then stored at $4^{\circ} \mathrm{C}$ until required.

\section{Kefir grains}

Kefir grains were collected from households in northern Taiwan. In the laboratory, these were inoculated $(5 \% \mathrm{w} / \mathrm{v})$ and propagated in sterilized $\left(121^{\circ} \mathrm{C}\right.$ for $\left.15 \mathrm{~min}\right)$ reconstituted skimmed milk $(10 \% \mathrm{w} / \mathrm{v})$ or soyamilk at $20^{\circ} \mathrm{C}$ for $20 \mathrm{~h}$ with twice- or thrice-weekly transfers, and kept at $4^{\circ} \mathrm{C}$ or $-80^{\circ} \mathrm{C}$ for short- or long-term storage, respectively.

\section{Milk-kefir and soyamilk-kefir manufacture}

Milk-kefir and soyamilk-kefir were manufactured using sterilized $\left(121^{\circ} \mathrm{C}\right.$ for $\left.15 \mathrm{~min}\right)$ reconstituted skimmed milk $(10 \% \mathrm{w} /$ v) and soyamilk inoculated with $5 \%(\mathrm{w} / \mathrm{v})$ kefir grains respectively, before being incubated at $20^{\circ} \mathrm{C}$ for $20 \mathrm{~h}$. At the end of fermentation, milk-kefir and soyamilk-kefir were filtered through three layers of cheesecloth in order to remove the kefir grains, and then lyophilized and stored at $4^{\circ} \mathrm{C}$ until required.

\section{Animals}

Male golden Syrian hamsters were obtained from the National Laboratory Animal Breeding and Research Center, National
Science Council, Taipei, Taiwan, at 4 weeks of age. They were housed in plastic cages (four per cage) featuring a controlled temperature $\left(22 \pm 1^{\circ} \mathrm{C}\right)$ and relative humidity $(55 \pm 5 \%)$, and were maintained on a reverse $12 \mathrm{~h}$ dark (20.00-08.00 hours) and light (08.00-20.00 hours) cycle. They were fed laboratory rodent chow (No. 5001; Ralston Purina, St. Louis, MO, USA) for a period of 8 weeks prior to being assigned to one of eight dietary treatment groups (eight animals per group) on a weight-randomized basis and fed an experimental diet for 8 weeks. The hamsters were given free access to their experimental diets and water. All animal experimental procedures followed the Taiwanese Guide for the Care and Use of Laboratory Animals (National Science Council, 1994).

\section{Diets and experimental protocol}

The detailed compositions of the experimental diets are presented in Table 1, these compositions being based upon AIN-93M (Reeves et al. 1993). The skimmed-milk powder, lyophilized soyamilk powder, lyophilized milk-kefir powder and lyophilized soyamilk-kefir powder were added to the respective diets at the expense of sucrose and starch. Dietary materials were mechanically mixed, subdivided and packaged in sealed aluminium bags and stored at $4^{\circ} \mathrm{C}$ until use. All experimental diets contained similar amounts of protein, fat, carbohydrate, minerals and vitamins.

All animals were fed the experimental diets for a period of 8 weeks. Feed intake was measured daily, and hamster body weights were recorded weekly. In order to determine the levels of faecal bile acids and steroids, faecal samples were collected for the last $2 \mathrm{~d}$ of the experimental period, freezedried and then stored at $-80^{\circ} \mathrm{C}$ until required for analysis.

At the end of the 8-week feeding period, the food sources were removed from the cages, $16 \mathrm{~h}$ prior to anaesthetizing the animals with an intraperitoneal injection of sodium pentobarbital (Nembutal; Abbott Laboratories, Chicago, IL, USA). Blood samples were collected from the hamsters via the abdominal aorta, placed in sterile tubes and centrifuged at $2000 \mathrm{~g}$ for $10 \mathrm{~min}$ at $4^{\circ} \mathrm{C}$, following which the serum was collected for the determination of triacylglycerols, total cholesterol and HDL-cholesterol content. The liver was removed, washed in sterile saline solution $(0.9 \%)$, dried in filter paper, weighed and stored at $-80^{\circ} \mathrm{C}$ for to determine the triacylglycerol and cholesterol content at a later time.

\section{Determination of serum triacylglycerols, total cholesterol and HDL-cholesterol}

Serum total cholesterol and triacylglycerol levels were measured enzymatically with commercial kits (Sigma Diagnostic Cholesterol Total 352-20 and Sigma Diagnostic Triglycerides 336-20; Sigma Diagnostics, St Louis, MO, USA). HDL-cholesterol was measured subsequent to the precipitation of the apo B-containing lipoproteins with sodium phosphotungstate magnesium chloride, the supernatant fraction being assayed for cholesterol with a commercial kit (Sigma Diagnostic Cholesterol HDL 352-4; Sigma Diagnostics). Non HDL-cholesterol was determined by subtracting the HDL-cholesterol level from the total cholesterol level. 
Table 1. Composition of the experimental diets (\%)

\begin{tabular}{|c|c|c|c|c|c|c|c|c|}
\hline & \multicolumn{4}{|c|}{ Cholesterol-free diet } & \multicolumn{4}{|c|}{ Cholesterol-enriched diet } \\
\hline & Milk & Milk-kefir & Soyamilk & Soyamilk-kefir & Milk & Milk-kefir & Soyamilk & Soyamilk-kefir \\
\hline Maize starch & $46 \cdot 57$ & $46 \cdot 57$ & $46 \cdot 57$ & $46 \cdot 57$ & $46 \cdot 57$ & $46 \cdot 57$ & $46 \cdot 57$ & $46 \cdot 57$ \\
\hline Dextrinized maizestarch* & $9 \cdot 1$ & $10 \cdot 5$ & $15 \cdot 5$ & $15 \cdot 5$ & $8 \cdot 75$ & $10 \cdot 15$ & $15 \cdot 15$ & $15 \cdot 15$ \\
\hline Sucrose* & $10 \cdot 0$ & $10 \cdot 0$ & $8 \cdot 5$ & 9.5 & $10 \cdot 0$ & $10 \cdot 0$ & $8 \cdot 5$ & $9 \cdot 5$ \\
\hline Soyabean oil* & 4 & 4 & 2 & 2 & 4 & 4 & 2 & 2 \\
\hline AIN-93M-MX† & 3.5 & 3.5 & 3.5 & $3 \cdot 5$ & 3.5 & 3.5 & 3.5 & 3.5 \\
\hline AIN-93-VX† & 1 & 1 & 1 & 1 & 1 & 1 & 1 & 1 \\
\hline L-Cystine & 0.18 & 0.18 & 0.18 & $0 \cdot 18$ & 0.18 & 0.18 & 0.18 & 0.18 \\
\hline Choline bitartrate & 0.25 & 0.25 & 0.25 & 0.25 & 0.25 & 0.25 & 0.25 & 0.25 \\
\hline t-Butylhydroquinone & 0.0008 & 0.0008 & 0.0008 & 0.0008 & 0.0008 & 0.0008 & 0.0008 & 0.0008 \\
\hline Cholesterol & 0 & 0 & 0 & 0 & 0.35 & 0.35 & 0.35 & 0.35 \\
\hline Skimmed milk powder & 10 & 0 & 0 & 0 & 10 & 0 & 0 & 0 \\
\hline Lyophilized milk-kefir & 0 & 10 & 0 & 0 & 0 & 10 & 0 & 0 \\
\hline Lyophilized soyamilk-kefir & 0 & 0 & 0 & 10 & 0 & 0 & 0 & 10 \\
\hline
\end{tabular}

${ }^{*}$ Casein, dextrinized maizestarch, sucrose, soyabean oil and cellulose were adjusted in terms of the contents of proteins, carbohydrates and fats in milk, milk-kefir, soyamilk and soyamilk-kefir.

† Mineral mixture AIN-93M-MX and vitamin mixture AIN-93-VX were obtained from ICN Biomedicals (Aurora, OH, USA).

For details of diets and procedures, see p. 940

\section{Determination of liver cholesterol}

Liver lipids were extracted according to the method of Folch et al. (1957). The liver total cholesterol and triacylglycerol concentrations were measured as described earlier.

\section{Quantification of faecal bile acids and neutral sterols}

Faecal total bile acids were determined according to the method of Xiao et al. (2003) with some modification. Milled freezedried faeces $(0.05 \mathrm{~g})$ were extracted twice with $3.5 \mathrm{ml}$ ethanol at $80^{\circ} \mathrm{C}$ for a period of $1 \mathrm{~h}$. Following two such extractions, the combined liquid phase was evaporated under $\mathrm{N}$ gas. The resulting pellet was dissolved in $200 \mu \mathrm{l} 3 \mathrm{M}-\mathrm{NaOH}$ and heated to $100^{\circ} \mathrm{C}$ for $2 \mathrm{~h}$, following which the mixture was cooled, the $\mathrm{pH}$ adjusted to 9 using $3 \mathrm{M}-\mathrm{NaOH}$ and the resulting mixture adjusted to a volume of $1 \mathrm{ml}$ using $0 \cdot 1 \mathrm{M}$-Tris buffer. A volume of sample $(10 \mu \mathrm{l})$ was then used to determine the total bile acid concentration enzymatically using a commercial kit (Sigma Diagnostic Bile Acids 450A; Sigma Diagnostics).

Faecal neutral sterols were extracted and saponified according to the method of Grundy et al. (1965), and analysed as trimethylsilyl ethers using GLC (model DE Educational; Dani, Monza, Italy) fitted with a SPB-1 Fused Silica Capillary column (30 m, 0.32 mm internal diameter; Supelco, Belfonte, PA, USA) using $5 \alpha$-cholestane as the internal standard. The column temperature was set at $220^{\circ} \mathrm{C}$, and the injector and flame ionization detector temperatures at $250^{\circ} \mathrm{C}$; the carrier gas was $\mathrm{N}$ set at a flow rate of $1 \mathrm{ml} / \mathrm{min}$.

\section{Statistical analysis}

All results were analysed using the general linear model procedure available from the Statistical Analysis System software package version 8.1 (Statistical Analysis System Institute, 1998). Duncan's multiple range test (Montgomery, 1991) was used to detect differences between treatment means. All the serum and liver lipid, faecal bile acid and sterol analyses were conducted in triplicate. The data were considered significantly different when $P<0 \cdot 05$.

\section{Results}

Food intake and body weight gain

There were no significant differences in mean final body weight, mean body weight gain, mean food intake or food efficiency ratio among the cholesterol-free diet groups during the 8 weeks of the experiment $(P>0.05$; Table 2$)$. There was also no significant difference in these parameters between the cholesterol-enriched diet groups, but the final body weights and body weight gains in the cholesterol-enriched diet groups were significantly greater than the corresponding values for the cholesterol-free diet groups (Table 2).

\section{Serum lipid concentrations}

For hamsters fed on the cholesterol-free diet, serum triacylglycerol and total cholesterol levels in the milk-kefir, soyamilk and soyamilk-kefir diet groups were significantly lower than the corresponding values for the milk diet group (Table 3). Serum HDL-cholesterol concentrations for the milk-kefir and soyamilk-kefir diet groups were significantly greater than for the milk diet group. Moreover, hamsters from the soyamilkkefir diet groups revealed lower concentrations of nonHDL-cholesterol than was the case for the soyamilk diet groups (Table 3 ).

The addition of cholesterol to the diet of study animals increased serum lipid levels, although the ingestion of milkkefir, soyamilk or soyamilk-kefir appeared to decrease serum total cholesterol and triacylglycerol. In particular, the reduction of cholesterol in the milk-kefir, soyamilk and soyamilk-kefir diet groups was reflected in lower non-HDL-cholesterol levels than was the case for the milk diet group. Moreover, the serum HDL-cholesterol levels for individuals from the cholesterolenriched milk-kefir, soyamilk and soyamilk-kefir diet groups 
Table 2. Body weight and feed intake of hamsters fed on cholesterol-free or cholesterol-enriched diets containing milk, milk-kefir, soyamilk or soyamilk-kefir

(Mean values and standard deviations)

\begin{tabular}{|c|c|c|c|c|c|c|c|c|}
\hline & \multicolumn{2}{|c|}{ Milk } & \multicolumn{2}{|c|}{ Milk-kefir } & \multicolumn{2}{|c|}{ Soyamilk } & \multicolumn{2}{|c|}{ Soyamilk-kefir } \\
\hline & Mean & SD & Mean & SD & Mean & SD & Mean & SD \\
\hline \multicolumn{9}{|l|}{ Cholesterol-free diet } \\
\hline Initial body weight (g) & $126 \cdot 96$ & 10.95 & $126 \cdot 17$ & 11.54 & $126 \cdot 88$ & $10 \cdot 44$ & $126 \cdot 50$ & $9 \cdot 61$ \\
\hline Final body weight (g) & $139 \cdot 03$ & $8 \cdot 85$ & $140 \cdot 28$ & $10 \cdot 54$ & $139 \cdot 3$ & $8 \cdot 34$ & 138.49 & $8 \cdot 20$ \\
\hline Body weight gain $(\mathrm{g} / \mathrm{d})$ & 0.22 & 0.09 & 0.25 & 0.07 & 0.22 & 0.08 & 0.21 & 0.06 \\
\hline Feed intake $(\mathrm{g} / \mathrm{d})$ & 8.51 & $1 \cdot 17$ & $8 \cdot 68$ & $1 \cdot 23$ & $8 \cdot 50$ & 1.08 & 8.99 & $1 \cdot 15$ \\
\hline Feed efficiency & 0.03 & 0.01 & 0.03 & 0.01 & 0.03 & 0.01 & 0.02 & 0.01 \\
\hline \multicolumn{9}{|l|}{ Cholesterol-enriched diet } \\
\hline Initial body weight (g) & $126 \cdot 43$ & 11.92 & $126 \cdot 13$ & $11 \cdot 01$ & $126 \cdot 03$ & 9.53 & $126 \cdot 05$ & 11.56 \\
\hline Final body weight (g) & $158 \cdot 21$ & $14 \cdot 18$ & $158 \cdot 14$ & $8 \cdot 84$ & $160 \cdot 14$ & $13 \cdot 50$ & $159 \cdot 29$ & 11.89 \\
\hline Body weight gain $(\mathrm{g} / \mathrm{d})$ & 0.57 & 0.13 & 0.57 & 0.06 & 0.61 & 0.11 & 0.59 & 0.15 \\
\hline Feed intake $(\mathrm{g} / \mathrm{d})$ & $7 \cdot 77$ & 0.97 & $7 \cdot 67$ & 1.03 & $7 \cdot 70$ & $1 \cdot 16$ & 7.85 & 1.02 \\
\hline Feed efficiency & 0.07 & 0.02 & 0.08 & 0.01 & 0.08 & 0.02 & 0.08 & 0.02 \\
\hline
\end{tabular}

For details of diets and procedures, see p. 940.

were significantly greater than the corresponding value for the milk-diet group $(P<0 \cdot 05$; Table 3$)$.

\section{Liver weight, hepatic cholesterol and triacylglycerol}

There were no significant differences in the dry liver weight and hepatic triacylglycerol contents between the cholesterolfree diet groups. There was also no significant difference in these parameters among the cholesterol-enriched diet groups. However, for both the cholesterol-free and cholesterolenriched diets, the hepatic total cholesterol concentrations for the milk-kefir, soyamilk and soyamilk-kefir diet groups were significantly lower than the corresponding value for the milk diet groups (Table 4).

\section{Faecal bile acid and neutral sterol excretion}

For both the cholesterol-free diet and the cholesterol-enriched diet, the concentrations of total faecal bile acids for the milk-kefir, soyamilk and soyamilk-kefir diet groups were significantly greater than was the case for the milk diet group (Table 5). Similar to the result observed for total bile acids, the total levels of faecal neutral sterols in the milk-kefir, soyamilk and soyamilk-kefir diet groups were significantly greater than the corresponding value for the milk diet group (Table 5). 'Total faecal neutral sterols' refers to the sum of coprostanol, cholesterol, dihydrocholesterol, campesterol and sitosterol. In general, hamsters from the soyamilk-kefir diet groups excreted cholesterol and dihydrocholesterol the most, whereas hamsters from the milk diet group excreted them the least (Table 5).

\section{Discussion}

The present results showed that the final body weight and body-weight gain of the cholesterol-enriched diet groups were significantly greater than the corresponding values for the cholesterol-free diet groups (Table 2). Such a result

Table 3. Serum lipid concentrations in hamsters fed on cholesterol-free or cholesterol-enriched diets containing milk, milk-kefir, soyamilk or soyamilk-kefir

(Mean values and standard deviations)

\begin{tabular}{|c|c|c|c|c|c|c|c|c|}
\hline & \multicolumn{2}{|c|}{ Milk } & \multicolumn{2}{|c|}{ Milk-kefir } & \multicolumn{2}{|c|}{ Soyamilk } & \multicolumn{2}{|c|}{ Soyamilk-kefir } \\
\hline & Mean & SD & Mean & SD & Mean & SD & Mean & SD \\
\hline \multicolumn{9}{|l|}{ Cholesterol-free diet } \\
\hline Triacylglycerol (mmol/l) & 3.29 & $0 \cdot 18^{a}$ & $2 \cdot 62$ & $0.34^{b}$ & $2 \cdot 22$ & $0.24^{c}$ & $2 \cdot 29$ & $0.21^{\mathrm{c}}$ \\
\hline Total cholesterol (mmol/l) & $5 \cdot 39$ & $0.85^{a}$ & 4.88 & $0.50^{b}$ & 3.96 & $0.24^{c}$ & 3.64 & $0.29^{c}$ \\
\hline HDL-cholesterol (mmol/l) & $2 \cdot 24$ & $0 \cdot 23^{c}$ & $2 \cdot 82$ & $0.30^{\mathrm{a}}$ & 2.45 & $0.30^{\mathrm{bc}}$ & 2.59 & $0.27^{\mathrm{ab}}$ \\
\hline Non-HDL-cholesterol (mmol/l) & $3 \cdot 15$ & $0.67^{a}$ & 2.06 & $0 \cdot 27^{b}$ & 1.51 & $0.08^{\mathrm{C}}$ & 1.06 & $0 \cdot 10^{d}$ \\
\hline Atherogenic index ${ }^{*}$ & $1 \cdot 40$ & $0 \cdot 22^{\mathrm{a}}$ & 0.73 & $0.09^{b}$ & 0.63 & $0 \cdot 12^{\mathrm{b}}$ & 0.41 & $0.07^{c}$ \\
\hline \multicolumn{9}{|l|}{ Cholesterol-enriched diet } \\
\hline Triacylglycerol (mmol/l) & 4.49 & $0.64^{a}$ & 3.88 & $0.85^{b}$ & 3.44 & $0.40^{\mathrm{bc}}$ & $3 \cdot 33$ & $0.44^{\mathrm{c}}$ \\
\hline Total cholesterol (mmol/l) & 7.59 & $0.39^{a}$ & $6 \cdot 81$ & $0.64^{b}$ & 6.45 & $0.72^{\mathrm{b}}$ & $6 \cdot 13$ & $0.54^{\mathrm{c}}$ \\
\hline HDL-cholesterol ( $\mathrm{mmol} / \mathrm{l})$ & 3.20 & $0.35^{b}$ & 3.76 & $0.44^{\mathrm{a}}$ & 3.85 & $0.38^{a}$ & 3.98 & $0 \cdot 19^{a}$ \\
\hline Non-HDL-cholesterol (mmol/l) & $4 \cdot 38$ & $0.09^{a}$ & 3.05 & $0 \cdot 29^{b}$ & $2 \cdot 60$ & $0.35^{\mathrm{c}}$ & $2 \cdot 15$ & $0.39^{d}$ \\
\hline Atherogenic index ${ }^{*}$ & $1 \cdot 38$ & $0 \cdot 15^{\mathrm{a}}$ & 0.82 & $0.09^{b}$ & 0.67 & $0.04^{c}$ & 0.54 & $0.09^{d}$ \\
\hline
\end{tabular}

a,b,c,d Mean values within a row with unlike superscript letters were significantly different $(P<0.05)$.

${ }^{*}$ Calculated as the ration of non-HDL-cholesterol to HDL-cholesterol.

For details of diets and procedures, see p. 940. 
Table 4. Liver lipid concentrations in hamsters fed on cholesterol-free or cholesterol-enriched diets containing milk, milk-kefir, soyamilk, or soyamilk-kefir

(Mean values and standard deviations)

\begin{tabular}{|c|c|c|c|c|c|c|c|c|}
\hline & \multicolumn{2}{|c|}{ Milk } & \multicolumn{2}{|c|}{ Milk-kefir } & \multicolumn{2}{|c|}{ Soyamilk } & \multicolumn{2}{|c|}{ Soyamilk-kefir } \\
\hline & Mean & SD & Mean & SD & Mean & SD & Mean & SD \\
\hline \multicolumn{9}{|l|}{ Cholesterol-free diet } \\
\hline Dry liver wt (g) & 4.74 & $0.33^{a}$ & 4.82 & $0.54^{a}$ & 4.83 & $0.54^{a}$ & $4 \cdot 73$ & $0.35^{a}$ \\
\hline Total cholesterol $(\mathrm{mg} / \mathrm{g})$ & $11 \cdot 28$ & $0.66^{a}$ & $10 \cdot 05$ & $0.86^{b}$ & $10 \cdot 22$ & $0.65^{\mathrm{b}}$ & $9 \cdot 76$ & $0.86^{b}$ \\
\hline Triacylglycerol $(\mathrm{mg} / \mathrm{g})$ & $28 \cdot 46$ & $1 \cdot 60^{\mathrm{a}}$ & $28 \cdot 23$ & $1 \cdot 33^{\mathrm{a}}$ & $28 \cdot 87$ & $1 \cdot 27^{\mathrm{a}}$ & $28 \cdot 31$ & $1.73^{a}$ \\
\hline \multicolumn{9}{|l|}{ Cholesterol-enriched diet } \\
\hline Dry liver wt $(\mathrm{g})$ & $7 \cdot 13$ & $0.59^{a}$ & $6 \cdot 45$ & $0.46^{\mathrm{a}}$ & $6 \cdot 66$ & $0 \cdot 88^{a}$ & $6 \cdot 83$ & $0.75^{a}$ \\
\hline Total cholesterol (mg/g) & 32.95 & $3.68^{a}$ & 29.64 & $2 \cdot 72^{\mathrm{b}}$ & $26 \cdot 62$ & $1.67^{\mathrm{c}}$ & 24.58 & $3 \cdot 86^{c}$ \\
\hline Triacylglycerol $(\mathrm{mg} / \mathrm{g})$ & 36.91 & $3 \cdot 20^{a}$ & 36.84 & $2 \cdot 56^{\mathrm{a}}$ & 36.99 & $2.95^{\mathrm{a}}$ & 36.96 & $2 \cdot 48^{\mathrm{a}}$ \\
\hline
\end{tabular}

${ }^{a, b, c}$ Mean values within a row with unlike superscript letters were significantly different $(P<0.05)$.

For details of diets and procedures, see p. 940.

would appear to be consistent with the study of Iwai et al. (2002), the results of which suggested that the addition of cholesterol to the diet of hamsters increased their body weight more than was the case for the cholesterol-free diet groups.

The ratio of LDL-cholesterol:HDL-cholesterol is commonly calculated in order to assess the risk of CHD, on the basis of evidence that an elevated LDL-cholesterol concentration is atherogenic, whereas a greater level of HDL-cholesterol is cardioprotective (Castelli et al. 1986). In the present study, the non-HDL-cholesterol level was calculated instead, because LDL-cholesterol accounts for most of the cholesterol in the non-HDL-cholesterol figure for hamsters. The decrease in the ratio of non-HDL-cholesterol:HDL-cholesterol indicated that milk-kefir, soyamilk and soyamilk-kefir diets may have a useful effect upon lipid metabolism and will probably favourably modulate the serum lipid profile.

The results of the present study appear to conflict with those of St-Onge et al. (2002), which indicated that kefir consumption did not result in lowered plasma lipid concentrations in a clinical trial. It is well known that different strains of lactic acid bacteria may have different effects on serum cholesterol concentration (Anderson \& Gilliland, 1999). The microbial composition of kefir grains has been reported to show population variations depending on the origin of the grains, the cultivation method and the manufacturing method (Pintado et al. 1996). Therefore, these conflicting results with kefirs may be due to the difference in kefir grains used in the experimental study. In addition, kefir was given to hypercholesterolaemic hamsters for 8 weeks in the present study. However, hypocholesterolaemic men were given kefir supplementation for only 4 weeks in St-Onge et al.'s (2002) study. It is possible that a hypocholesterolaemic effect in human subjects might have been observed had kefir been given for a long period, as was done in the present study.

The mechanisms underlying the hypocholesterolaemic activity of lactic acid bacteria have been proposed to involve an inhibition of exogenous cholesterol absorption from the

Table 5. Faecal bile acid and neutral sterols excretion in hamsters fed on cholesterol-free or cholesterolenriched diets containing milk, milk-kefir, soyamilk or soyamilk-kefir

(Mean values and standard deviations (mg/d per hamster))

\begin{tabular}{|c|c|c|c|c|c|c|c|c|}
\hline & \multicolumn{2}{|c|}{ Milk } & \multicolumn{2}{|c|}{ Milk-Kefir } & \multicolumn{2}{|c|}{ Soyamilk } & \multicolumn{2}{|c|}{ Soyamilk-kefir } \\
\hline & Mean & SD & Mean & SD & Mean & SD & Mean & SD \\
\hline \multicolumn{9}{|l|}{ Cholesterol-free diet } \\
\hline Total bile acid & 1.07 & $0.15^{d}$ & $1 \cdot 29$ & $0.28^{c}$ & $2 \cdot 46$ & $0.25^{\mathrm{b}}$ & 2.94 & $0.25^{\mathrm{a}}$ \\
\hline Total neutral sterols & $1 \cdot 16$ & $0.13^{d}$ & $1 \cdot 30$ & $0.11^{c}$ & $2 \cdot 20$ & $0.14^{\mathrm{b}}$ & $2 \cdot 35$ & $0.07^{a}$ \\
\hline Coprostanol & 0.35 & $0.05^{a}$ & 0.34 & $0.05^{a}$ & 0.36 & $0.03^{a}$ & 0.33 & $0.04^{a}$ \\
\hline Cholesterol & 0.20 & $0.03^{d}$ & 0.26 & $0.05^{c}$ & 0.56 & $0.06^{b}$ & 0.63 & $0.05^{a}$ \\
\hline Dihydrocholesterol & 0.20 & $0.03^{d}$ & 0.25 & $0.03^{c}$ & 0.30 & $0.07^{b}$ & 0.38 & $0.06^{a}$ \\
\hline Campesterol & 0.28 & $0.04^{b}$ & 0.31 & $0.04^{b}$ & 0.54 & $0.06^{a}$ & 0.56 & $0.04^{a}$ \\
\hline Sitosterol & 0.14 & $0.02^{b}$ & 0.14 & $0.03^{b}$ & 0.45 & $0.03^{a}$ & 0.46 & $0.02^{a}$ \\
\hline \multicolumn{9}{|l|}{ Cholesterol-enriched diet } \\
\hline Total bile acid & $1 \cdot 27$ & $0.16^{d}$ & $1 \cdot 54$ & $0.17^{c}$ & 2.58 & $0 \cdot 18^{b}$ & $3 \cdot 16$ & $0.23^{a}$ \\
\hline Total neutral sterols & 1.66 & $0.11^{d}$ & $1 \cdot 86$ & $0 \cdot 10^{c}$ & 2.95 & $0.11^{\mathrm{b}}$ & 3.08 & $0.08^{a}$ \\
\hline Coprostanol & 0.63 & $0.03^{b}$ & 0.64 & $0.04^{\mathrm{ab}}$ & 0.68 & $0.05^{a}$ & 0.65 & $0.05^{a b}$ \\
\hline Cholesterol & 0.35 & $0.07^{d}$ & 0.43 & $0.08^{\mathrm{C}}$ & 0.86 & $0.06^{b}$ & 0.94 & $0.08^{a}$ \\
\hline Dihydrocholesterol & 0.21 & $0.03^{c}$ & 0.26 & $0.05^{b}$ & 0.35 & $0.03^{a}$ & 0.36 & $0.05^{a}$ \\
\hline Campesterol & 0.38 & $0.04^{c}$ & 0.38 & $0.05^{c}$ & 0.60 & $0.05^{\mathrm{b}}$ & 0.64 & $0.05^{a}$ \\
\hline Sitosterol & 0.13 & $0.03^{c}$ & 0.15 & $0.03^{c}$ & 0.46 & $0.05^{b}$ & 0.49 & $0.03^{a}$ \\
\hline
\end{tabular}

a,b,c,d Mean values within a row with unlike superscript letters were significantly different $(P<0.05)$.

For details of diets and procedures, see p. 940. 
small intestine, by binding of the cholesterol and bile acids to the bacterial cells and by the assimilation of cholesterol, as well as by suppressing bile acid resorption by deconjugation as a function of bacterial bile salt hydrolase activity (Xiao et al. 2003). Vujicic et al. (1992) reported that kefir culture possessed the ability to assimilate cholesterol in milk. In the present study, we demonstrated that milk-kefir feeding brought about a significant lowering of the serum concentrations of total cholesterol, non-HDL-cholesterol and triacylglycerol, in comparison with the milk diet, suggesting that this might be attributable, in part, to the ability of the micro-organisms contained within the kefir grains to assimilate cholesterol.

The major metabolites of cholesterol in the body are bile acids; therefore, a greater excretion of bile acids should, in principle, lead to a lower serum cholesterol level (Ho et al. 2003). It has previously been hypothesized that a deconjugation of bile acids may contribute to a lower plasma cholesterol level. Deconjugated bile acids are excreted in the faeces, whereas conjugated bile acids are recycled to the liver via the enterohepatic circulation (Gilliland, 1990). In vitro experiments have demonstrated that some strains of Lactobacillus produce the enzyme bile salt hydrolase and have the capacity to deconjugate bile acids (Gilliland et al. 1985). In the present study, we found that the excretion of total bile acids in the faeces was significantly greater for the milk-kefir diet group than for the milk diet group. Such a result may be attributable to bile salt hydrolase activity and the bile acid-binding ability of the micro-organisms present in the kefir grains.

Iwami et al. (1986) reported a correlation between the hydrophobicity of a protein hydrolysate and its ability to bind to bile acids, and Choi et al. (2002) reported that a 129-134-residue region in soya glycinin (11S globulin) played an important role by binding to bile acids. Sugano et al. (1990) demonstrated that an undigested high-molecular-weight fraction of soya protein, obtained following a microbial protease treatment, bound bile salts in vitro and revealed a significant hypocholesterolaemic effect in vivo. These results support the hypothesis that a peptide featuring high bile acid-binding capacity could inhibit the reabsorption of bile acids in the ileum and thus decrease the blood cholesterol level. In a previous study, we found that L. helveticus isolated from kefir grains possessed high proteolytic activity (Lin et al. 1999). It may thus be that the higher faecal bile acid excretion of the soyamilk-kefir diet group than of the other dietary groups was attributable in part to the peptides deriving from soya proteins.

The present results showed that the total levels of faecal neutral sterols in the milk-kefir, soyamilk and soyamilk-kefir diet groups were significantly greater than the corresponding value for the milk diet group (Table 5). In general, hamsters from the soyamilk-kefir diet groups excreted cholesterol and dihydrocholesterol the most, whereas hamsters from the milk diet group excreted them the least. It has been postulated by Nagata et al. (1982) that the degree of serum cholesterol-lowering activity elicited by soya protein depends upon the resulting degree of faecal sterol excretion. In this study, we demonstrated a higher faecal neutral sterol excretion for hamsters fed on a soyamilk-kefir diet than for hamsters fed alternative diets, indicating that such an effect is, at least in part, due to an enhancement of faecal sterol excretion.
Many nutritional and medical investigations have revealed the great potential of soya protein in lowering serum cholesterol level (Carroll \& Kurowska, 1995; Demonty et al. 2003; Ascencio et al. 2004). Several mechanisms have been suggested to underlie the cholesterol-lowering effect of soya products, including the enhancement of bile acid excretion, increased tissue LDL-receptor activity and a reduced absorption of dietary cholesterol (Potter, 1995). To the best of our knowledge, however, the exact mechanism by which the dietary intake of soya product decreases plasma cholesterol level is still not fully understood. Two hypotheses for such a mechanism have been the subject of quite some debate: cholesterollowering as a direct effect of the major isoflavones present in soyabeans (particularly daidzein and genistein) or, alternatively, a direct effect of the protein components (mainly $\beta$-conglycinin from soyabeans or their fragments; Lovati et al. 2000).

The cholesterol-lowering properties of isoflavones have been supported by experimental and, in part, by clinical findings. It has previously been reported that isoflavones elicit an inhibitory action upon tyrosine kinase, which is a major regulator of LDL receptor activity in liver cells, and also that tyrosine kinase might exert a reducing effect on LDL levels (Lovati et al. 2000). Recent reports, however, have not demonstrated any effect of dietary supplementation with isoflavone-rich soya extract upon plasma lipids and lipoproteins (Demonty et al. 2003). Nestel et al. (1997) reported that when isoflavones from soya were consumed without its protein component, the anticipated lipid-lowering effect was generally not observed. In a previous study, we found that the kefir fermentation process did not normally affect the concentration of genistein in soyamilk significantly (Liu et al. $2002 b$ ). Therefore, the increase in the cholesterol-lowering effect of soyamilk-kefir compared with soyamilk might be attributable to hypocholesterolaemic compounds other than genistein present in the kefir and absent from soyamilk.

In addition to soya isoflavones, a number of other soya protein components have been shown to be able to elicit a cholesterol-lowering effect. For example, Nagaoka et al. (1999) reported that a peptic hydrolysate of soya protein featured a cholesterol-lowering effect similar to that of intact soya protein. Not all soya peptides may be fully degraded by digestive enzymes such as trypsin and peptidase in the intestinal lumen, such enzyme-resistant soya peptides possibly demonstrating properties similar to those of dietary fibre with regard to the ability to bind to bile acids and cholesterol, and thus increase their faecal excretion.

Lovati et al. (1992) reported that soya $\beta$-conglycinin (7S globulin) stimulated the expression of LDL receptors and the degradation of LDL by hepatocytes in vitro. These researchers also found that some small peptides produced by the enzymatic digestion of soya protein have the same effects (Lovati et al. 2000). In the present study, we found that soyamilk-kefir appeared to have a greater non-HDL cholesterol lowering effect than soyamilk, but only a similar effect on triacylglycerol level (Table 3), suggesting that this may be attributable, in part, to the soya protein-derived peptides, which increased LDL receptor activity but had no effect on the activities of enzymes involved in fatty acid synthesis. The actual situation remains the subject of future research. 
Not only have soya protein-derived peptides been reported to lower serum cholesterol, but this is also the case for milk-protein-derived peptides. Yoshikawa et al. (2000) reported that a low-molecular-weight peptide, $\alpha$-lactotensin (His-Ile-Arg-Leu), derived from $\beta$-lactoglobulin, reduced serum cholesterol in mice subsequent to oral administration. Nagaoka et al. (2001) reported that a new peptide (Ile-IleAla-Glu-Lys) derived from $\beta$-lactoglobulin was able to significantly influence serum cholesterol levels in rats, and exhibited a more-pronounced hypocholesterolaemic effect than was the case for $\beta$-sitosterol, a proprietary medicine specifically manufactured to lower serum cholesterol level. As indicated earlier, we found in a previous study that L. helveticus isolated from kefir grains demonstrated substantial proteolytic activity (Lin et al. 1999). It would thus appear to be appropriate for future studies to focus upon the hypocholesterolaemic or other bioactive peptides produced in milk or soyamilk during fermentation by kefir grains.

Nakajima et al. (1992) found that the consumption of milk fermented with a certain exopolysaccharide-producing lactic acid bacterium significantly decreased serum cholesterol levels in rats, whereas the consumption of milk fermented with a non-exopolysaccharide-producing strain did not elicit such an effect. These authors suggested that this was because the bacterial exopolysaccharide acted in a manner similar to that of dietary fibre and reduced the absorption of cholesterol and bile acids in the intestine. Pigeon et al. (2002) demonstrated that two exopolysaccharide-producing strains of $L$. delbrueckii ssp. bulgaricus bound significantly greater amounts of bile acids than was the case for the non-exopolysaccharide-producing strains. Maeda et al. (2004) reported that an exopolysaccharide produced by $L$. kefiranofaciens reduced serum cholesterol level in rats when they consumed excessive dietary cholesterol.

The polysaccharide kefiran is found uniquely in kefir, and some researchers believe that kefiran is its active ingredient (Shiomi et al. 1982; Maeda et al. 2004). The composition of the kefiran from soyamilk-kefir grains differs from that of the kefiran from milk-kefir grains (Liu et al. 2002a), but, to the best of our knowledge, comprehensive information specific to the hypocholesterolaemic properties of kefiran still appears to be lacking. Thus, further investigation is required in order to verify the hypocholesterolaemic properties of kefiran and the effect of polysaccharide composition on these.

\section{References}

Anderson JW \& Gilliland SE (1999) Effect of fermented milk (yogurt) containing Lactobacillus acidophilus L1 on serum cholesterol in hypercholesterolemic humans. J Am Coll Nutr 18, 43-50.

Angulo L, Lopez E \& Lema C (1993) Microflora present in kefir grains of the Galician region (north-west of Spain). J Dairy Res 60, 263-267.

Ascencio C, Torres N, Isoard-acosta F, Gomez-Perez NF, HernandezPando R \& Tovar AR (2004) Soy protein affects serum insulin and hepatic SREBP-1 mRNA and reduces fatty liver in rats. J Nutr 134, $522-529$.

Carroll KK \& Kurowska EM (1995) Soy consumption and cholesterol reduction: review of animal and human studies. J Nutr 125, 594S-597S
Castelli WP, Garrison RJ, Wilson PWF, Abbott RD, Kalousdian S \& Kannel WB (1986) Incidence of coronary heart disease and lipoprotein cholesterol levels: the Framingham Study. J Am Med Assoc 256, 2835-2838.

Choi SK, Adachi M \& Utsumi S (2002) Identification of the bile acidbinding region in the soy glycinin $\mathrm{A} 1 \mathrm{aB} 1 \mathrm{~b}$ subunit. Biosci Biotechnol Biochem 66, 2395-2401.

Demonty I, Lamarche B \& Jones PJH (2003) Role of isoflavones in the hypocholesterolemic effect of soy. Nutr Rev 61, 189-203.

de Roos NM, Schouten G \& Katan MB (1998) Yoghurt enriched with Lactobacillus acidophilus does not lower blood lipids in healthy men and women with normal to borderline high serum cholesterol levels. Eur J Clin Nutr 53, 277-280.

Farnworth ER \& Mainville I (2003) Kefir: a fermented milk product. In Handbook of Fermented Functional Foods, pp. 77-111 [ER Farnworth, editor]. Boca Raton, FL: CRC Press.

Folch J, Lees M \& Sloane-Stanley GH (1957) A simple method for the isolation and purification of total lipids from animal tissues. J Biol Chem 226, 497-509.

Gilliland SE (1990) Health and nutritional benefits from lactic acid bacteria. FEMS Microbiol Rev 87, 175-188.

Gilliland SE, Nelson CR \& Maxwell C (1985) Assimilation of cholesterol by Lactobacillus acidophilus. Appl Environ Microbiol 49, 377-381.

Grundy SM, Ahrens EH \& Miettinen TA (1965) Quantitative isolation and gas liquid chromatography analysis of total faecal bile acids. J Lipid Res 6, 397-410.

Hasler CM (2002) The cardiovascular effects of soy products. $J$ Cardiovasc Nurs 16, 50-63.

Ho HM, Leung LK, Chan FL, Huang Y \& Chen ZY (2003) Soy leaf lowers the ratio of non-HDL to HDL cholesterol in hamsters. $J$ Agric Food Chem 51, 4554-4558.

Iwai K, Nakaya N, Kawasaki Y \& Matsue H (2002) Antioxidative functions of natto, a kind of fermented soybeans: effect on LDL oxidation and lipid metabolism in cholesterol-fed rats. J Agric Food Chem 50, 3597-3601.

Iwami K, Sakakibara K \& Ibuki F (1986) Involvement of post-digestion 'hydrophobic' peptides in plasma cholesterol-lowering effect of dietary plant proteins. Agric Biol Chem 50, $1217-1222$.

Lin CW, Chen CL \& Liu JR (1999) Identification and characterisation of lactic acid bacteria and yeasts isolated from kefir grains in Taiwan. Aust J Dairy Technol 54, 14-18.

Liu JR, Chen MJ \& Lin CW (2002a) Characterization of polysaccharide and volatile compounds produced by kefir grains grown in soymilk. J Food Sci 67, 104-108.

Liu JR, Chen MJ \& Lin CW (2005) Antimutagenic and antioxidant properties of milk-kefir and soymilk-kefir. J Agric Food Chem 53, 2467-2474.

Liu JR, Wang SY, Lin YY \& Lin CW (2002b) Antitumor activity of milk-kefir and soymilk-kefir in tumor-bearing mice. Nutr Cancer 44, 182-187.

Lovati MR, Manzoni C, Corsini A, Granata A, Frattini R, Fumagalli R \& Sirtori CR (1992) Low-density receptor activity is modulated by soybean globulins in cell culture. J Nutr 122, 1971-1978.

Lovati MR, Manzoni C, Gianazza E, Arnoldi A, Kurowska E, Carroll KK \& Sirtori CR (2000) Soy protein peptides regulate cholesterol homeostasis in Hep G2 cells. J Nutr 130, 2543-2549.

Maeda H, Zhu X, Omura K, Suzuki S \& Kitamura S (2004) Effects of an exopolysaccharide (kefiran) on lipids, blood pressure, blood glucose, and constipation. Biofactors 22, 197-200.

Mann GV \& Spoerry A (1974) Studies of a surfactant and cholesterolemia in the Maasai. Am J Clin Nutr 27, 464-469.

Marshall VM \& Cole WM (1985) Methods for making kefir and fermented milks based on kefir. J Dairy Res 52, 451-452.

Montgomery DC (1991) Experiments with a single factor: the analysis of variance. In Design and Analysis of Experiments, 
pp. 75-77 [DC Montgomery, editor]. New York, NY: John Wiley $\&$ Sons.

Nagaoka S, Futamura Y, Miwa K, Awano T, Yamauchi K, Kanamaru Y, Tadashi K \& Kuwata T (2001) Identification of novel hypocholesterolemic peptides derived from bovine milk $\beta$-lactoglobulin. Biochem Biophys Res Commun 281, 11-17.

Nagaoka S, Miwa K, Eto M, Kuzuya Y, Hori G \& Yamamoto K (1999) Soy protein peptic hydrolysate with bound phospholipids decreases micellar solubility and cholesterol absorption in rats and Caco-2 cells. J Nutr 129, 1725-1730.

Nagata Y, Ishiwaki N \& Sugano M (1982) Effects of arginine and lysine addition to casein and soya-bean protein on serum lipids apolipoproteins insulin and glucagon in rats. $J$ Nutr 112, $1614-1625$.

Nakajima H, Suzuki Y \& Hirota T (1992) Cholesterol-lowering activity of ropy fermented milk. J Food Sci 57, 1327-1329.

National Science Council (1994) Guide for the Care and Use of Laboratory Animals. Taipei, Taiwan, Republic of China: National Science Council.

Nestel PJ, Yamashita T, Sasahara T, Pomeroy S, Dart A, Komesaroff P, Owen A \& Abbey M (1997) Soy isoflavones improve systemic arterial compliance but not plasma lipids in menopausal and perimenopausal women. Arterioscler Thromb Vasc Biol 17, 3392-3398.

Pigeon RM, Cuesta EP \& Gilliland SE (2002) Binding of free bile acids by cells of yogurt starter culture bacteria. J Dairy Sci $\mathbf{8 5}$, 2705-2710.

Pintado ME, Lopes Da Silva JA, Fernandes PB, Malcata FX \& Hogg TA (1996) Microbiological and rheological studies on Portuguese kefir grains. Int J Food Sci Technol 31, 15-26.

Potter SM (1995) Overview of proposed mechanisms for the hypocholesterolemic effect of soy. J Nutr 125, 606S-611S.
Reeves PG, Nielsen FH \& Fahey GCJ (1993) AIN-93 purified diets for laboratory rodents: final report of American Institute of Nutrition ad hoc writing committee on the reformulation of the AIN76A rodent diets. J Nutr 123, 1939-1951.

Shiomi M, Sakaki K, Murofushi M \& Aibara K (1982) Antitumor activity in mice of orally administered polysaccharide from kefir grain. Jpn J Med Sci Bio. 35, 75-80.

Statistical Analysis System Institute (1998) SAS User's Guide: Statistics. Cary, NC: SAS Institute Inc.

St-Onge MP, Farnworth ER \& Jones PJH (2000) Consumption of fermented and nonfermented dairy products: effects on cholesterol concentrations and metabolism. Am J Clin Nutr 21, 149-151.

St-Onge MP, Farnworth ER, Savard T, Chabot D, Mafu A \& Jones PJH (2002) Kefir consumption dose not alter plasma lipid levels or cholesterol fractional synthesis rates relative to milk in hyperlipidemic men: a randomized controlled trial. BMC Complement Altern Med 2, 1-7.

Sugano M, Goto S, Yamada Y, Yoshida K, Hashimoto Y, Matsuo T \& Kimoto M (1990) Cholesterol-lowering activity of various undigested fractions of soybean protein in rats. J Nutr 120, 977-985.

Vujicic IF, Vulic M \& Konyves T (1992) Assimilation of cholesterol in milk by kefir cultures. Biotechnol Lett 14, 847-850.

Xiao JZ, Kondo S, Takahashi N, Miyaji K, Oshida K, Hiramatsu A, Iwatsuki K, Kokubo S \& Hosono A (2003) Effects of milk products fermented by Bifidobacterium longum on blood lipids in rats and healthy adult male volunteers. J Dairy Sci 86, $2452-2461$.

Yoshikawa M, Fujita H, Matoba N, Takenaka Y, Yamamoto T, Yamaushi R, Tsuruki H \& Takahata K (2000) Bioactive peptides derived from food proteins preventing lifestyle-related diseases. Biofactors 12, 143-146. 